\title{
A perspectiva do lazer entre lideranças sindicais das áreas metropolitanas de São Paulo e de Lisboa
}

\author{
Luiz Gonçalves Junior ${ }^{1}$ \\ Fabio Ricardo Mizuno Lemos ${ }^{2}$ \\ Denise Aparecida Corrêa ${ }^{3}$ \\ ${ }^{1}$ Departamento de Educação Física e Motricidade Humana e PPGE da UFSCar, São \\ Carlos, SP, Brasil \\ ${ }^{2}$ Centro Universitário Claretiano de Batatais e UFSCar, São Carlos, SP, Brasil \\ ${ }^{3}$ UNESP - Univ Estadual Paulista, Departamento de Educação Física, Bauru, SP, Brasil \\ e Diretora Científica da Sociedade de Pesquisa Qualitativa em Motricidade Humana, São \\ Carlos, SP, Brasil
}

\begin{abstract}
Resumo: Pretendemos, neste estudo, compreender qual o sentido do lazer, diante das novas relações de trabalho em tempos de globalização, para líderes sindicais que atuam em entidades das áreas metropolitanas de São Paulo/Brasil e de Lisboa/Portugal. A metodologia adotada foi a Fenomenologia, Fenômeno Situado. Com base nos dados originados nas entrevistas, estabelecemos as seguintes categorias temáticas: A) Busca da redução da jornada de trabalho, B) Usufruto do lazer, C) Lazer como recuperação para o trabalho. Consideramos que nos tempos de globalização, após diversas conquistas dos trabalhadores, infelizmente, temos assistido nas últimas décadas, crescente precarização de direitos dos trabalhadores nos dois países pesquisados, gerando insegurança do trabalhador diante da vivência do seu trabalho e do seu lazer de modo autônomo, livre, criativo, significativo e humanizado.
\end{abstract}

Palavras-Chave: Lazer. Trabalho. Sindicalistas. Globalização.

The perspective of the leisure amoung syndicalists of the metropolitans areas of São Paulo and Lisbon

\begin{abstract}
We intended, in this study, to understand the sense of the leisure, due to the new work relationships in times of globalization, for syndical leaders that act in entities of metropolitan areas of São Paulo (Brazil) and Lisbon (Portugal). The methodology used was Phenomenology, Situated Phenomenon. Based on the data originated in the interviews, we established the following thematic categories: A) The request for the reduction of the work day, B) Actions related to the use of the leisure, C) Leisure as recovery for the work. We consider that in the globalization times, after diverse conquests of the workers, unhappily, we have attended in the last few decades, increasing precariousness of rights of the workers in the two searched countries, generating unreliability of the worker ahead of the experience of its work and of its leisure in independent way, it exempts, creative, significant and humanized.
\end{abstract}

Keywords: Leisure. Work. Syndicalists. Globalization.

\section{Introdução}

A observação atenta ao cotidiano urbano das grandes cidades nos coloca diante de muitos paradoxos, dentre os quais destacamos para discutirmos neste artigo, aquele que envolve 0 lazer e, indissociável a este, o trabalho e as novas relações que se processam nesses campos na atual sociedade globalizada.

O dia a dia dos habitantes das áreas metropolitanas tem sido marcado pela pressa, pela urgência em chegar ao trabalho e, em alguns casos, sair muito tempo depois do término deste.

A discussão conceitual que envolve o lazer e sua relação com o "tempo livre", como a que aponta Dumazedier (1973), cujo conceito clássico sugere a dicotomia do tempo de lazer em relação ao tempo dedicado às outras esferas da vida do sujeito (trabalho, relações familiares e sociais), tem suscitado críticas e proposições que superem essa compreensão dicotômica.

Marcellino (1996), por exemplo, propõe o lazer como cultura vivenciada no "tempo disponível", adotando tal expressão como referência ao tempo "livre", por considerar que este tempo, dado os contextos social e econômico atuais, nem sempre se concretiza como realmente "livre".

Adorno (1995) ironiza a expressão "tempo livre", e afirma que o sujeito exerce exatamente o oposto a suposta liberdade, uma vez que a sociedade, de maneira conjuntural, direciona o que o sujeito vai ou não fazer neste e em outros tempos, inclusive no tempo de trabalho, pois para 
ele, também neste, os sujeitos não "dispõem de si mesmos com real liberdade" dadas as circunstâncias de determinada realidade social em que o sujeito está inserido.

Concordamos com Gonçalves Junior e Santos (2006), os quais entendem o lazer prioritariamente enquanto intencionalidade do "sendo-uns-com-osoutros-ao-mundo", como possibilidade da:

[...] conscientização e autonomia do ser. Implicando, portanto, em uma escolha que depende do significado atribuído pelo ser ao lazer (e ao trabalho!), não desconsiderando o contexto sócio-político, que envolve opressão (de uns sobre outros) e desigualdades (entre uns e outros) conforme se dá nas relações entre pessoas, grupos, comunidades, sociedades e nações, desenvolvidas com certas finalidades e em certos espaços e tempos (GONCALVES JUNIOR; SANTOS, 2006, p. 1903).

Assim, para nós o lazer é entendido como um fenômeno indissociável das demais esferas da vida dos sujeitos e, na presente pesquisa, temos como objetivo central compreender o sentido atribuído ao lazer por líderes sindicais que atuam em entidades das áreas metropolitanas de São Paulo/Brasil e de Lisboa/Portugal no universo das novas relações de trabalho em tempos de globalização.

\section{O movimento sindical no Brasil e em Portugal}

Após o término da Primeira Guerra Mundial ocorreu o surgimento de diversos governos ditatoriais, tendendo a centralizar o poder nas mãos de um único governante, e contando com o respaldo de grupos militares em diversos países: Hitler, na Alemanha; Mussolini, na Itália; Franco, na Espanha; Salazar, em Portugal e Vargas, no Brasil, são exemplos deste fenômeno (GONÇALVES JUNIOR, 2008).

Em Portugal ocorre golpe de estado em 28 de maio de 1926, liderado por António de Oliveira Salazar, destacando-se como principais pretextos, segundo Rosário (1996), a instabilidade política e a crise econômica, associada ao desejo de regresso ao poder de monárquicos e republicanos que não compartilhavam das ideias do governo de então. Salazar só é deposto em 25 de abril de 1974 com a Revolução dos Cravos.

No Brasil, é com a ascensão de Getúlio Dornelles Vargas à Presidência da República em 1930 que ocorre a caracterização dos chamados sindicatos estatais. Vargas, também chamado "pai do sindicalismo" ou "pai dos pobres" em decorrência da promulgação de diversas leis de natureza social-paternal (em particular a $\mathrm{CLT}^{1}$ ), realiza golpe de estado em 1937 e se mantém no governo do Brasil através da ditadura denominada "Estado Novo" até 1945, quando é deposto (GONÇALVES JUNIOR, 2008).

Segundo Lima et al. (1992) depois da época revolucionária do anarco-sindicalismo do início do século $X X$, Portugal mergulhou num processo de aparente letargia, cortado pelo Estado Novo Salazarista e pelos fluxos migratórios observados, sobretudo na década de 1960. Ainda assim, algumas manifestações operárias eclodiram na vigência do Estado Novo, nomeadamente com o suporte do Partido Comunista Português, o que acabou por possibilitar-lhe a ocupação de vários sindicatos antes mesmo do 25 de Abril, bem como formar a base de sustentação da Central Geral dos Trabalhadores Portugueses Intersindical Nacional (CGTP-IN), que foi central exclusiva entre 1970 e 1978, surgindo, apenas em 1978, a União Geral dos Trabalhadores (UGT).

Logo após o término do Estado Novo português, o movimento operário teve grande força no país. Descreve Lima (1999) que ocorreu uma verdadeira explosão de reivindicações laborais e pela primeira vez foi fixado um salário mínimo nacional, generalizaram-se complementos salariais, férias pagas, $13^{\circ}$ e $14^{\circ}$ salário-mês.

Para o sindicalista Gianotti (1988), a estrutura sindical brasileira é um corpo de leis articuladas para garantir o controle do Estado que nem mesmo com o golpe militar de 1964 foram alteradas, servindo muito bem aos interesses governamentais dos generais ditadores.

Particularmente nas Áreas Metropolitanas de São Paulo e Lisboa (centros econômicos do Brasil e de Portugal) foi possível identificar pronunciado desenvolvimento dos setores secundário e terciário, bem como uma maior resistência da população, dos estudantes, intelectuais e dos líderes sindicais a política ditatorial de ambos os países. Resistência esta que levou a perseguição e cassação de mandato de diversos sindicalistas, e mesmo o fechamento e/ou intervenção das respectivas entidades.

Tanto no Brasil como em Portugal, decorrente da influência, controle e centralização do poder vivido nos respectivos períodos ditatoriais (no Brasil: "estado novo", sob a ditadura de Vargas, entre 1937-1945, e "militar", sob a ditadura dos generais ditadores, entre 1964 e 1985; em

\footnotetext{
1 Sigla de Consolidação das Leis do Trabalho, aprovada por Vargas em $1^{\circ}$ de maio de 1943 através do Decreto-Lei no 5452.
} 
Portugal, "estado novo", sob a ditadura de Salazar, entre 1926 e 1974) o modelo sindical de ambos os países ainda guarda ranços de corporativismo.

Segundo o sindicalista Manuel Carvalho da Silva (2002) a sociedade portuguesa é ainda marcada por séculos de colonização de outros países, especialmente de modo mais negativo, durante os 48 anos da ditadura salazarista, o que entende prejudicar em muito o desenvolvimento mais profícuo de uma cultura de solidariedade nacional e, principalmente, internacional. Afirma ainda que os sindicatos portugueses andam muito ocupados com a defesa de condições mínimas de vida e proteção social, pois os baixos salários e o baixo nível de qualificação exigem "respostas que desgastam os sindicatos e limitam a sua intervenção" (p.36).

Para Rodrigues (1997) o movimento sindical do $A B C^{2}$, iniciado em fins da década de 1970, foi fator decisivo na luta pela redemocratização do Brasil, influenciando de forma significativa a fundação do Partido dos Trabalhadores (PT), em 1980, e da Central Única dos Trabalhadores (CUT), em 1983.

Acrescenta Rodrigues (1997) ser o Sindicato dos Metalúrgicos de São Bernardo a origem do chamado "novo sindicalismo", o qual coloca em questão o rompimento do alto controle exercido pela estrutura sindical corporativa, pouco a pouco desenvolvendo sua atividade junto às massas e se empenhado na solução dos problemas trabalhistas no interior das indústrias.

Afirma também Rodrigues (1997) que tal base seria uma das principais fontes do sindicalismo adotado pela CUT, em particular na década de 1980. Porém, com as mudanças no mundo do trabalho nos anos 1990, a crise econômica e social que o Brasil atravessou e o grau de institucionalização que a CUT acabou por engendrar levou esta central a uma postura mais contratual nas negociações, deixando um pouco de lado o discurso mais "confrontador" presente em suas origens. Em março de 1991, decorrente de ruptura da "Confederação Geral dos Trabalhadores" (CGT), origina-se a "Força Sindical" (FS) e com ela o chamado "sindicalismo de resultados", ou seja, negociar objetivando a conquista de benefícios, evitando ao máximo o confronto.

\footnotetext{
${ }^{2}$ A sigla se refere aos municípios de Santo André, São Bernardo do Campo e São Caetano do Sul, pertencentes à Área Metropolitana de São Paulo, os quais possuem alta concentração industrial, especialmente do ramo automobilístico.
}

No que diz respeito mais diretamente ao campo do lazer as centrais sindicais CUT e Força Sindical, do Brasil, e CGTP-IN e UGT, de Portugal, tem em comum a luta pela redução da jornada de trabalho. Quanto a criação e manutenção de equipamentos específicos de lazer (clubes, grêmios recreativos e colônias de férias) tem sido mais defendido no Brasil, pela Força Sindical e, em Portugal, pela UGT (GONÇALVES JUNIOR, 2008).

\section{Do taylorismo-fordismo às novas relações de trabalho em tempos de globalização}

Em fins do século XIX empresários e engenheiros passam a debater mudanças na organização do trabalho industrial, a qual, ao invés da exclusiva fundamentação na "experiência", deveria pautar-se pelo caráter "científico". Objetivava-se com isso, basicamente, aumentar a produção, reduzir os custos, fazer face à crescente concorrência e possibilitar 0 alargamento do consumo (GONÇALVES JUNIOR, 2008).

Os princípios da chamada organização "científica" do trabalho foram propostos pelo engenheiro mecânico estadunidense Frederic Winslow Taylor, o qual buscou aplicar no meio produtivo industrial os procedimentos do método experimental, que já gozava de grande prestígio em diversos ramos científicos à época, particularmente na física.

$\mathrm{O}$ que veio a se designar taylorismo colocou em causa os métodos tradicionais e procurou demonstrar que para se atingir a prosperidade máxima se fazia necessária a produtividade máxima, sendo para tanto indispensáveis: o treino; o aperfeiçoamento; a seleção dos operários mais capazes para as tarefas em que mais se adequam; definição correta e simplificada das tarefas; estímulos a produção através de prêmios (aumento de salário ou promoção) para os trabalhadores mais produtivos (MONIZ, 2002).

De acordo com Lima et al. (1992) tais procedimentos foram posteriormente desenvolvidos e implementados pelo empresário da emergente indústria estadunidense do automóvel, Henry Ford, particularmente na proposição da cadeia de montagem. Assim, ao invés do operário se deslocar, passa a sua frente o objeto que deve manufaturar, em um tempo determinado pela cadência da esteira.

O taylorismo-fordismo acabou por caracterizar o modelo de produção da indústria moderna entre as décadas de 1930 e 1960, obtendo, porém, seus melhores resultados após o término da 
Segunda Guerra Mundial, declinando a partir da década de 1970 com a crise internacional do petróleo e dos mercados produtoresconsumidores.

Afirma Lima et al. (1992) que à crise reagiram os empresários com a internacionalização da produção e do mercado, bem como com a introdução de novas tecnologias, enquanto os Governos generalizaram as políticas de austeridade. Gera-se, assim, procura da mobilidade na organização do trabalho: "precarização do emprego, flexibilidade dos custos salariais, eliminação dos obstáculos à reestruturação dos processos de trabalho, recuo do 'Estado de Bem-Estar"' (p.9).

Concomitante a este novo cenário passa a fazer parte da ordem do dia de políticos, empresários, trabalhadores, estudantes e pesquisadores o debate sobre a globalização, sendo tema de constantes manchetes $e$ reportagens dos diversos meios de comunicação. Normalmente a expressão vem associada a ideia de liberalização dos mercados nacionais, quebra de barreiras alfandegárias, desenvolvimento da competitividade na produção e distribuição de bens, culminando com a globalização da economia e, consequentemente, com a interdependência das diversas economias nacionais umas das outras em escala global (GONCALVES JUNIOR, 2008).

Diante desta nova situação histórica lanni (1997) afirma que tudo se desterritorializa: pessoas, palavras, imagens, línguas, religiões, culturas e, especialmente, a economia, entendida aqui como capitalismo. $\mathrm{Na}$ mesma escala globalizam-se os interesses e objetivos daqueles que detêm meios políticos, econômicos, sociais e culturais de mando e desmando em escala global.

Para Pais (2001) vivemos um momento de crise, entendida na contemporaneidade através do paradigma da indecisão. Tudo é instável: na economia vemos o domínio das flutuações das taxas de juros, das ações, dos câmbios e das bolsas; no âmbito do consumo assistimos a uma propensão desenfreada, suscetível de provocar uma obesidade consumista, a publicidade procura acelerar o consumo e ainda a "estética relativamente estável do modernismo fordista deu lugar a uma estética pós-modernista que celebra o efêmero, o instável, a precariedade" (p.20).

Segundo Observatório (2001), a crise petrolífera dos anos 1970, a concorrência cada vez maior do Japão e dos novos países industrializados, bem como o lançamento de diversos países em uma política de expansão para fazer frente à crise, marcaram profundamente a atividade econômica da época, colocando em causa formas tradicionais de organização do trabalho, tal como a produção fordista, até então dominante. "A sobrevivência (ou a competitividade) das empresas tornou-se função da respectiva flexibilidade, isto é, da capacidade em se adaptarem, de forma contínua e com custos reduzidos, às novas realidades emergentes" (p.27).

De acordo com Antunes (1999), especialmente a partir da década de 1980, percebe-se um grande desenvolvimento tecnológico nos processos de produção fabril dos países de industrialização avançada e intermediária, com destaque para a inserção da automação, da robótica e da informatização; ocorrendo uma flexibilização dos processos de produção, no qual - cronômetro e a produção em série, típicos do modelo fordista, são substituídos por novas formas de adequação da produção à lógica do mercado, introduzindo-se formas e expressões como gestão participativa, polivalência dos operários e busca da qualidade total.

Tais características são provenientes do modelo japonês denominado toyotismo ou ohnoismo (de Taiichi Ohno, nome do engenheiro que originou este modelo fabril na Montadora de Automóveis Toyota, no Japão, a partir dos anos 1950).

Para Lima (1999), associada às mudanças internas na gestão das empresas, têm ocorrido crise das instituições políticas e sociais tradicionais, fim dos regimes comunistas, reformas vultosas do chamado "EstadoProvidência", crescimento da terceirização dos assalariados e da feminização do mercado profissional.

Segundo Pais (2001), com os paradigmas de trabalho e economia em crise, se debate atualmente formas organizacionais que alcancem a competitividade do modelo toyotista japonês, porém não é possível acreditar ser tal modelo libertador, ao contrário tem sido classificado como management by stress; e é exatamente este estresse que tem permitido a intensificação dos ritmos de produção, mas pouco se tem discutido a respeito das sequelas do desgaste do trabalhador diante de tal estresse. Observa, porém, que o Supremo Tribunal Japonês recentemente criou a figura jurídica de "morte por estresse laboral", sendo que as empresas daquele país começam a ser responsabilizadas pelo karoshi (palavra japonesa com o significado de morte por excesso de trabalho).

Assim, Pais (2001) adverte que atualmente os trabalhadores circulam por uma infinidade de 
trabalhos precários, não havendo realidade que se encaixe no tradicional conceito de trabalho. Ao invés de uma rotina estável ou de uma carreira previsível há um enfrentamento com um mercado de trabalho flexível.

Apesar disto, tal modelo tem sido "exportado" do Japão para os demais países de capital globalizado, como Brasil e Portugal, acarretando, por hora, terceirização dos serviços, subcontratação e/ou flexibilização dos direitos do trabalhador, retração da ação sindical e, mais especificamente no caso brasileiro aumento dos índices de desemprego (GONCALVES JUNIOR, 2008).

Para Lima et al. (1992) o movimento operário característico da sociedade industrial vê-se ameaçado diante da entrada em um novo tipo de sociedade.

Os sindicatos estão distantes da nova realidade no domínio da organização do trabalho, que ainda não conhecem completamente. Além disso, a nova estratégia das administrações das corporações em abandonar a política de confronto, ao menos aberto às reivindicações salariais, tem desconcertado os sindicatos, ainda orientados dentro dos princípios fordistas de regulação salarial. Também tem enfraquecido os sindicatos a mobilização dos trabalhadores em torno do projeto da empresa, da sua identidade e cultura, valorizando a participação, que conjuntamente com práticas de individualização das remunerações e carreiras, levam ao estilhaçar de solidariedades e de uma consciência operária mais tradicional (LIMA et al., 1996).

A globalização traz consigo a busca de novos mercados não só para a venda, mas para a própria produção, sempre na ótica do menor tempo e gasto, assim busca-se países com mãode-obra barata e que detenham alguma tecnologia, para redução progressiva dos citados tempo e gasto, bem como do próprio efetivo de trabalhadores (GONCALVES JUNIOR, 2008).

Assim, a globalização da economia, o estabelecimento de novos padrões de consumo e a flexibilização da regulação do trabalho têm possibilitado a duras penas a sustentabilidade do capitalismo neste atual estágio, gerando situações de desemprego e de emprego precário.

No que se refere ao lazer, o estudo de Almeida e Gutierrez (2005) aponta que no contexto da globalização e especificamente no caso brasileiro, cuja distribuição de renda é altamente desigual, as possibilidades de fruição ficaram reduzidas à pequena parcela da população que tem à disposição a variedade de opções que o mercado do entretenimento globalizado e de alto padrão oferece, enquanto que: "As possibilidades de acesso ao lazer, por parte da população excluída e de baixa renda no Brasil, ficam cada vez mais restritas. Primeiro por falta de espaço, já que as ruas são palco da violência urbana, tornando a televisão o maior promotor do lazer" (p.49).

Atentamos que 0 trabalho alienado que percorre os modelos fordista e taylorista também percorre o modelo toyotista, e tal forma alienada se reproduz ainda na esfera do lazer. Tornando trabalho e lazer pouco significativos ao trabalhador.

Observamos, portanto, interferência direta desta nova dinâmica das relações de trabalho com relação à vida familiar, pessoal, comunitária e de lazer dos trabalhadores, o que nos instiga a investigar a compreensão de líderes de entidades sindicais das regiões metropolitanas de São Paulo/Brasil e Lisboa/Portugal sobre a prática social lazer, diante das novas relações de trabalho em tempos de globalização.

A preferência por discursos de líderes sindicais das citadas áreas metropolitanas, as quais, nos dois países foram marcadas por significativas e históricas lutas de entidades sindicais e dos trabalhadores e em torno da causa destes, se deu em virtude de se tratarem dos sujeitos eleitos pelos trabalhadores das respectivas categorias para serem seus representantes nos sindicatos, lutando pela defesa, manutenção e conquista de direitos trabalhistas.

Salientamos, ainda, estarmos vivendo contexto de intenso processo de transformação de sociedade urbano-industrial para sociedade informacional, em geral, com aparente maior "tempo disponível", porém se trabalhando no ritmo estressante/alucinante da informática, e ainda contando com aumento dos índices de desemprego causados, entre outros, pela evolução tecnológica e aumento da competitividade global, que tem levado as corporações a reduzirem seu quadro de funcionários para reduzir o custo final dos produtos, visando manutenção ou ampliação do lucro e forçando flexibilização das leis laborais, o que tem causado maior dificuldade na luta sindical.

\section{Metodologia}

Apenas indo à coisa mesma, ou seja, aos sujeitos situados na região de inquérito (lugar ontológico no qual se inserem conhecimentos específicos) e interrogando-os é que se poderá desvelar o fenômeno que se encontra oculto. A coisa (HUSSERL, 1988) possui existência e, 
então, perspectivas diversas que a deixam ser em sua plenitude.

Para Merleau-Ponty (1996), olhar o objeto é entranhar-se nele, porque:

[...] os objetos formam um sistema em que um não pode se mostrar sem esconder outros. Mais precisamente, o horizonte interior de um objeto não pode se tornar objeto sem que os objetos circundantes se tornem horizonte [...]. A estrutura objeto-horizonte, quer dizer, a perspectiva, não me perturba quando quero ver o objeto: se ela é o meio que os objetos têm de se dissimular, é também o meio que os objetos têm de se desvelar. [...] Em outros termos: olhar um objeto é vir habitá-lo (p.104-105).

A pesquisa pautada na fenomenologia não prima pelo estabelecimento de fatos, ou seja, de relações causais, mecânicas, mensuráveis; mas pelo desvelar dos fenômenos (do grego phainoumenon: luz que ilumina aquilo que está oculto) ou a consciência enquanto fluxo temporal de vivências, e cuja peculiaridade é a imanência (compreendido na própria essência do todo) e a capacidade de outorgar significado às coisas exteriores (TÁPIA, 1984).

Como afirma Martins (1992), "não conhecemos nossos próprios pensamentos até que formulamos numa expressão linguística interna, daí que é claro que o falar realiza o pensamento mais do que traduz um pensamento já pronto" (p.60).

Pretendemos neste estudo que o fenômeno se mostre como é, e este só se mostra através daqueles que o experienciam no seu mundo-vida e, portanto, Ihe dão existência ao atribuir significados.

Assim, o interrogar da pesquisa foi dirigido aos líderes de entidades sindicais das áreas metropolitanas de São Paulo/Brasil e Lisboa/Portugal propondo-lhes a seguinte interrogação: Qual o sentido do lazer diante das novas relações de trabalho em tempos de globalização?

Possibilitamos que falassem livremente e sem interrupções, gravando, após consentimento formal, seus discursos em fitas cassete magnéticas e posteriormente transcrevendo-os rigorosamente.

Os discursos coletados foram numerados com algarismos romanos relacionados à ordem de obtenção dos mesmos. A letra B após o algarismo indica os líderes sindicais da área metropolitana de São Paulo/Brasil e a letra $P$, os líderes sindicais da área metropolitana de Lisboa/Portugal.
Relacionamos abaixo os líderes sindicais entrevistados, cuja identificação nominal e da respectiva entidade da qual fazem parte, foram devidamente autorizadas pelos mesmos:

$\checkmark \quad$ IB - Aparecido Inácio da Silva (Cidão) Presidente do "Sindicato dos Trabalhadores nas Indústrias Metalúrgicas, Mecânicas, de Material Elétrico e Eletrônico, Siderúrgicas, Veículos e de Autopeças de São Caetano do Sul";

$\checkmark \quad$ IIB - Francisco Carlos da Conceição (Chicão) - Presidente do "Sindicato Profissional dos Empregados das Empresas de Segurança, Vigilância, Cursos de Formação de Vigilantes, Transportes de Valores e Segurança Pessoal Privada de Santo André, São Bernardo do Campo, São Caetano do Sul, Diadema, Mauá, Ribeirão Pires e Rio Grande da Serra";

$\checkmark \quad$ IIIB - Valdecir Fernandes da Silva (Véinho) - Presidente do "Sindicato dos Trabalhadores nas Indústrias Metalúrgicas, Mecânicas e Material Elétrico de Santo André, Mauá, Ribeirão Pires e Rio Grande da Serra";

$\checkmark$ IVB - Sérgio Novais - Presidente do "Sindicato dos Trabalhadores nas Indústrias Químicas e Similares de Santo André, São Bernardo do Campo e São Caetano do Sul";

$\checkmark \quad$ VB - Edison Luiz Bernardes - Presidente do "Sindicato dos Trabalhadores nas Indústrias da Construção e do Mobiliário de São Caetano do Sul";

$\checkmark \quad$ VIB - Vagner de Castro - Presidente do "Sindicato dos Trabalhadores em Empresas do Ramo Financeiro de Santo André, São Bernardo do Campo, São Caetano do Sul, Diadema, Mauá, Ribeirão Pires e Rio Grande da Serra";

$\checkmark \quad$ VIIB - José Lopes Feijó - Presidente do "Sindicato dos Trabalhadores nas Indústrias Metalúrgicas, Mecânicas, de Material Elétrico e de Autopeças de São Bernardo do Campo";

$\checkmark$ IP - Adriano Matoso - Secretário Nacional da "Federação Intersindical da Metalurgia, Metalomecânica, Minas, Química, Farmacêutica, Petróleo e Gás";

$\checkmark \quad$ IIP - Paulo Alexandre Martins Gonçalves Coordenador do "Sindicato dos Trabalhadores dos Transportes Rodoviários e Urbanos do Centro";

$\checkmark \quad$ IIIP - José Manuel Rodrigues de Oliveira Dirigente do "Sindicato Nacional dos Trabalhadores do Sector Ferroviário";

$\checkmark$ IVP - Américo da Rosa Flora Marques Coordenador do "Sindicato dos Trabalhadores das Indústrias Metalúrgicas e Metalomecânicas do Sul";

$\checkmark$ VP - Manuel Joaquim Fresquilho Camacho - Coordenador do "Sindicato dos Bancários do Sul e llhas";

$\checkmark \quad$ VIP - Domingos Barão Paulino - Secretário Geral do "Sindicato dos Trabalhadores dos Transportes Rodoviários e Afins";

$\checkmark \quad$ VIIP - Joaquim Martins - Secretário Geral do "Sindicato da Construção, Obras Públicas e Serviços Afins". 
A metodologia adotada foi a fenomenológica (MERLEAU-PONTY, 1996), modalidade fenômeno situado (MARTINS; BICUDO, 1989; GONCALVES JUNIOR, 2008), sendo que após a transcrição minuciosa e na íntegra dos discursos realizamos a identificação das unidades de significado (asserções significativas para 0 pesquisador diante da interrogação empreendida), as quais possibilitaram a redução fenomenológica (movimento em busca da síntese, entendida como essência do discurso), para posterior organização das categorias (formadas no transcorrer da redução a partir das convergências, divergências ou idiossincrasias observadas nos discursos dos sujeitos) para posterior construção dos resultados (fase na qual apresentamos uma compreensão do fenômeno interrogado).

\section{Construção dos Resultados}

A seguir, as categorias são analisadas, sendo utilizados excertos dos discursos dos sujeitos, os quais desvelam suas perspectivas do fenômeno lazer sob novas relações de trabalho em tempos de globalização.

\section{Categoria A) Busca da redução da jornada de trabalho}

A luta pela redução da jornada de trabalho se apresenta como a principal ação no âmbito do lazer, como indica um dos sujeitos: "[...] isso é uma luta que a maioria dos sindicatos vem travando" (IIB-3).

Observamos que embora haja a expectativa de que com a redução da jornada o trabalhador terá "mais tempo de [...] lazer, [...] mais tempo pra sua família, [...] pra sair do estresse do dia a dia" (IB-1), outros relatos apontam que a conquista do tempo disponível não assegura o aumento na fruição do lazer, pois:

[...] introdução de novas tecnologias, não corresponde [...] a uma menor jornada de trabalho para todos e, portanto, a manutenção de postos de trabalho, pelo contrário significa, maior capacidade de produção, com ritmos mais intensos que mesmo com jornadas menores demandam menor volume de mão de obra. Quem fica, portanto, no mercado de trabalho se extenua mais, submetido a novas formas de tensão e a novos ritmos e, como contrapartida, ainda aumenta o volume de pessoas desempregadas" (VIIB-8).

E como menciona outro trabalhador: "pensamos que [...] apesar de ter se dado alguns avanços na [...] redução da jornada de trabalho, isto não têm significado que haja maior disponibilidade para o trabalhador" (IIIP-7).
Um aspecto que perpassa essa categoria é a menção da redução da jornada como uma ação que visa, também, a preservação de postos de trabalho, pois: "além de você proporcioná um lazer maior [...], você também cria [...] uma situação [...] mais adequada pra evitá a perda de mais postos de trabalho" (IB-9).

[...] quando começô a briga da redução da jornada de trabalho, entre os objetivos [...] você tinha, o trabalhador [...] mais tempo pra ficá com a sua família, tempo para o lazer e ao mesmo tempo você tinha uma política de geração de emprego (VB-3).

Os relatos indicam que atrelado à luta pela diminuição da jornada, a busca por melhor remuneração é imprescindível, para que a pessoa "nesse tempo maior que ela vai ter [...], ela possa aplicar um pouco desse tempo para o seu estudo, para sua qualificação, mas também que ela possa ter mais lazer" (IVB-5).

[...] lutamos pela redução dos horários de trabalho, mas também lutamos pela valorização dos salários, pela melhoria das condições de trabalho; [...] apesar da redução da jornada de trabalho o trabalhador cada vez continua a estar mais ocupado e a ter menos tempo disponível pra si e [...] para a família (IIIP-8).

Outro aspecto relacionado à redução da jornada de trabalho é a dificuldade para o desencadeamento de ações visando conquistá-la, como indicam os excertos a seguir: "[...] cada vez existe mais individualidade entre os trabalhadores [...]. As pessoas pensam em si! Não pensam como se pensava a vinte ou trinta anos atrás! [...] que havia uma unidade entre os trabalhadores" (VIP-2). "Tivemos grande sucesso [...] nesse [...] final da década de 80 e 90 e temos tido sim uma grande dificuldade hoje de fazê mais acordos de redução de jornada." (IVB-8). "[...] com esse retrocesso, $[\ldots]$ o patronato ganha alguma força e - patronato procura limpar das convenções colectivas, [...] praticamente todos os direitos existentes" (IP-6). "O que eles costumam dizer é: "nós só admitimos isto quando vier na lei, quando a lei nos impuser [...]'. Mesmo a tal da redução do horário de trabalho [...]" (VIIP-8).

No tocante à flexibilização do horário de trabalho, há menção acerca da legislação portuguesa que desfavorece os trabalhadores:

\footnotetext{
Existe de facto uma propensão [...] em termos da contratação colectiva [...] de haver a flexibilidade do horário de trabalho em termos [...] anuais e [...] obrigatoriedade de trabalhar aos sábados (IVP-2).

[...] a lei determina que o trabalhador no pico industrial passa a ter um horário flexível, em função das necessidades da empresa. Quer dizer que ele pode trabalhar $6,8,[\ldots]$ até 10 horas diárias [...] os horários de trabalho passam a ser praticamente todos 10 horas!" (IIIP-6).
} 


\section{Categoria B) Usufruto do lazer}

Quanto às possibilidades de usufruto do lazer, notamos que, embora os relatos mencionem ações visando concretizá-las, também percebemos, a partir dos discursos dos líderes sindicais, apontamentos significativos acerca das dificuldades e/ou impossibilidades que se colocam à fruição do lazer, as quais estão sendo identificadas com a letra "d" logo após o número da unidade de significado, representando divergência.

No que se refere às ações relacionadas ao usufruto do lazer, percebemos dois níveis, um diz respeito às ações das entidades sindicais, outro às ações do próprio trabalhador.

Entre as ações relacionadas as entidades sindicais temos: construção e manutenção de colônias de férias e clubes de campo; realização de excursões, campeonatos esportivos e de jogos de tabuleiro; indicação de roteiros de atividades culturais e de lazer em jornais distribuídos aos trabalhadores.

Há o apontamento da necessidade de construir relações, de se organizar coletivamente para uma luta sindical em busca do atendimento de reivindicações que incluem o lazer, como demonstram os excertos: "[...] o trabalhador e a categoria ela tem que tá sempre buscando novos caminhos, seja [...] na perspectiva do trabalho, na de lazer" (IIIB-7); "Nós temos em nossas reivindicações o aumento do período de férias" (IP-2); "[...] conseguimos em alguns sítios mais um dia ou dois de férias anuais" (VIIP-7).

No entanto, identificamos uma divergência no relato do sujeito VB quando afirma que: "[...] acaba se mantendo [...] naquela política de você tê a colônia de férias, fazê um ou outro campeonato [...] pra atraí os associados" (13d). Nesse caso, a finalidade que se propõe na ação da entidade não é efetivamente o lazer, mas sim a atração de associados.

Enquanto ações pessoais do trabalhador destacaram passeios a cinemas, teatros, parques e shoppings como afirmou um dos entrevistados: "A região tem shoppings [...] shopping hoje virou um pouco [...] área de lazer das pessoas" (VIIB17). Outro destacou espaços que funcionam em tempo integral e aos finais de semana como possibilidades para o trabalhador usufruir o lazer:

A região tem muitos parques, [...] alguns até que ficam abertos 24 horas por dia, onde as pessoas podem fazer caminhada, [...] piqueniques ou que podem tá indo com a família [...] No final de semana [...] você tem [...] áreas pra praticar esporte [...] e os trabalhadores se aproveitam, digamos destas facilidades da região (VIIB-14).
Também realizaram asserções sobre realização de jogos de futebol e churrascos, porém, esta atividade em particular veio associada a construção, reforma ou ampliação de residências de trabalhadores através do jargão bater uma laje: "[...] o lazer [...] dos trabalhadores na realidade, acaba sendo o churrasquinho no final de semana quando ele bate uma laje" (VB-9), demonstrando a necessidade de abrigo para família, na medida do possível fruindo o lazer com os amigos e familiares. O sindicalista IIP também mencionou o convívio com amigos e familiares: "Posso ir à um bar tomar um copo, estar ali com os amigos" (12).

Viagens a praia e ao campo foram destacadas, como pelo sindicalista VP: "[...] no verão das quatro e meia até as nove horas é dia e as pessoas podem utilizar e ir na praia ou no campo" (10).

Por outro lado encontramos relatos de não haver e/ou estar dificultada a possibilidade de fruir - lazer, em dois discursos de sindicalistas brasileiros: "[...] essa questão do lazer ainda não é uma coisa que [...] a gente pode dizê assim, [...] o trabalhador [...] médio do Brasil, ele [...] ainda não tem esse direito consagrado" (VB-4d); "[...] de uma forma geral, as condições de vida do trabalhador envolvida às suas relações de [...] lazer nesse ambiente de globalização [...] vêm se deteriorando" (VIB-1d).

No caso da realidade portuguesa, três entrevistados foram ainda mais contundentes ao mencionarem que: "[...] com relação aos tempos de lazer eu achei [...] alguma piada [...] [Risos]. Quer dizer, não há tempos de lazer. [...] Os portugueses não os têm!" (IIP-6d). Concordando com ele, outro entrevistado menciona que "[...] lazer [...] em Portugal é [...] complicado [...] porque de facto nesta era da globalização nós temos sido confrontados [...] essencialmente com o patronato a retirar direitos, incluindo o de lazer" (IP-1d). E ainda diz outro entrevistado: "[...] a análise que nós fazemos é a experiência do dia a dia, e [...] nos diz que cada vez temos menos tempo disponível de lazer" (IIIP-9d).

A situação financeira foi outro aspecto destacado pelos sindicalistas entrevistados no que diz respeito a fruição do lazer, conforme as seguintes asserções: "[...] cada vez mais, mais trabalhadores passam as férias em casa, não têm dinheiro para ir em outros lugares, mesmo aqui dentro, já não tem nada a ver com o estrangeiro!" (IIP-7d). Isto porque "[...] os salários estão extremamente reduzidos." (IIP-1d); “[...] O [...] salário [...] foi tão achatado [...], que essa 
condição pra ele podê [...] tê lazer [...] tá cada vez mais difícil." (VB-7d). O sindicalista VB prossegue:

[...] nós sabemos muito bem que a questão do lazer, hoje no Brasil é muito ligada à questão financeira. Se você tem uma situação financeira mais bem definida, você tem [...] condição [...] de se programá pra tê suas férias, pra sê sócio de um clube do seu bairro (VB-11d).

Mais que a problemática financeira, 0 sindicalista IIP acrescenta que: "As pessoas além de não terem dinheiro, pura e simplesmente não têm o tempo. Porque as cargas horárias são demasiada excessivas" (5d). Isto porque:

Ou trabalha ou faz trabalho suplementar ou tem aquilo que nós designamos pelo [...] gancho [...] E que a pessoa sai do seu respectivo local de trabalho depois tem um pequeno trabalhinho, um part-time, de forma a poder ganhar mais algum dinheiro (IIP-4d).

\section{Categoria C) Lazer como recuperação para o trabalho}

Nesta categoria é atribuída ao lazer, pelos sindicalistas entrevistados, a função relacionada à compensação dos desgastes sofridos pelos trabalhadores no labor: "aumentar a qualidade de vida pós-laboral, para que de facto eles possam combater, através do lazer, a grande pressão que [...] todos os trabalhadores sofrem globalmente em todo o mundo" (VP-3).

No caso da realidade brasileira há, inclusive, ações neste sentido, como explicita um dos relatos:

[...] a gente [...] tem discutido, por exemplo, no final de ano, é trinta dias de férias, ao invés de ser vinte e dez em dinheiro [...] é uma forma [...] do trabalhador tê o lazer, tê seu descanso, pra pegá uma jornada anual aí de trabalho [...] pesado (IIIB-5).

Desta forma, o lazer também evitaria "[...] diversos distúrbios de cunho [...] emocional, [...] diversos distúrbios que vem prejudicando a saúde do trabalhador, pela falta de oportunidades de lazer [...] essas questões relacionadas a tê uma boa saúde mental" (VIB-5).

Tais ações visam a recuperação da força de trabalho, uma vez que "[...] você produziria mais porque você teria uma pessoa descansada [...] com a mente mais arejada [...] teria menos problemas relacionados à estresse, [...] à cansaço" (VB-17).

\section{Considerações}

Com base na Construção dos Resultados foi possível perceber que não ocorreu a formação de categorias distintas entre as Centrais Sindicais Brasileiras e Portuguesas.
Todas as asserções formadoras da categoria "A) Busca da redução da jornada de trabalho" foram convergentes, o que revela uma preocupação dos líderes sindicais dos dois países com o aumento da possibilidade de usufruto do lazer, mas também, com a garantia de mais postos de trabalho. Corroborando com tal dado, estudo anterior de Gonçalves Junior (2008) demonstra que duas das centrais sindicais brasileiras (Central Única dos Trabalhadores CUT - e Força Sindical - FS) e duas das centrais sindicais portuguesas (Confederação Geral dos Trabalhadores Portugueses - Intersindical Nacional - CGTP-IN - e União Geral dos Trabalhadores - UGT) são unânimes na defesa da redução da jornada de trabalho semanal.

A dificuldade de ações visando a conquista da redução também foi apontada pelos líderes sindicais, ao relatarem experiência junto aos empresários, os quais justificam não possibilidade de redução da jornada de trabalho decorrente da globalização da economia e do aumento da competitividade, fazendo-se ainda necessária, segundo estes, a flexibilização das relações laborais para evitar demissões.

Relacionado ao tema da redução da jornada de trabalho, há mais de um século, mais precisamente em 1880, Paul Lafargue, publicava o seu "O Direito à Preguiça", no qual se opunha firmemente a mitificação do trabalho, para ele cerceador da plena realização humana. Para Lafargue (1999) as pessoas não devem trabalhar mais do que 3 horas diárias, para assim terem efetivamente tempo para a poesia, a música, a pintura, os jogos e os exercícios corporais. Mais que isso, em sua compreensão, deste modo haveria trabalho para todos, assim, aqueles que estavam desempregados também poderiam trabalhar e, por outro lado, aqueles que não trabalham (os patrões) por viverem à custa do trabalho de outrem, também deveriam trabalhar.

Anos depois da publicação de Lafargue, Bertrand Russell apresenta o seu "O Elogio ao Ócio" (1932), no qual afirma se fazer necessária à redução da jornada de trabalho para 4 horas diárias, possibilitando caminho para a felicidade e para a prosperidade humana (RUSSELL, 2001).

Para além destas inestimáveis contribuições, não menos significativo, na luta pela redução da jornada de trabalho, é o histórico movimento grevista dos trabalhadores da cidade de Chicago (EUA), nos idos de 1886, ao exigirem a divisão do dia em três oitos: 8 horas de trabalho, 8 horas de descanso e 8 horas de lazer. Movimento este que originou as comemorações do $1^{\circ}$ de Maio, "Dia Internacional dos Trabalhadores", que vem sendo 
ideologicamente tratado como "Dia do Trabalho", retirando-se o ser humano que realiza a prática social do trabalho do foco central das reflexões.

Atualmente a França possui jornada de trabalho de 35 horas semanais, em Portugal e no Brasil, no entanto, a jornada é de 40 e 44 horas respectivamente. Ressaltamos que Centrais Sindicais destes dois países tem na pauta de suas reivindicações a redução da jornada de trabalho constitucional para 35 horas (Portugal) e 40 horas (Brasil), propostas bastante tímidas diante das de Lafargue e Russell, que ainda assim, no entanto, têm enfrentado extremas dificuldades para efetiva consolidação.

Para a categoria "B) Ações relacionadas ao usufruto do lazer", os líderes sindicais fizeram referências às ações das entidades sindicais (colônias de férias, clubes de campo, organização de excursões, campeonatos, entre outros) assim como às ações do próprio trabalhador (passeios a shoppings e parques, viagens para praia e campo, convívio com amigos e familiares, entre outros).

Encontramos, nesta categoria divergências, uma no tocante às ações das entidades sindicais no depoimento do sindicalista VB que remeteram às ações desenvolvidas pelo sindicato objetivando atração de maior número de associados, sendo um fim diverso a fruição do lazer.

Quanto as possibilidades de vivenciar o lazer, identificamos divergências das asserções coletadas, relacionadas às dificuldades envolvendo tempo escasso, baixo poder aquisitivo e desemprego. Os líderes sindicais compreendem que o fenômeno contemporâneo da globalização tem tido sua ênfase centrada na economia, causando impactos negativos na dimensão social, interferindo, inclusive, na fruição do lazer.

Ações relacionadas à vivência do lazer têm sido difíceis, em decorrência das dinâmicas sociais dominantes, aos fortes ritmos de trabalho que têm sido impostos para alguns conjuntos de profissionais e pela lógica do consumo instalada com a sociedade globalizada.

Atualmente alguns trabalhadores, devido à baixa remuneração, acúmulo de atividades e sedução pelo consumo, prolongam sua jornada de trabalho diária para além da convencionalmente regulamentada, tornando rotina as conhecidas horas extras e os não menos praticados trabalhos secundários, os chamados "bicos", no Brasil, ou os "biscates", como nomeiam os portugueses. De acordo com Corrêa (2002), as horas extras por vezes funcionam, inclusive, como estratégia para escapar dos dissabores da maratona diária dos horários de pico ao retornar para casa.

Podemos dizer que, na atual sociedade, cada vez mais se acentuam os valores ligados à cultura de consumo, na qual o imaginário social encontrase fragmentado e é estimulado pelo princípio do rendimento e eficiência de mercado, transformando tudo (e todos!) em mercadoria, incluindo o lazer, originando a chamada indústria do lazer e do turismo.

Mais recentemente, temos assistido em diversos países 0 surgimento de empreendimentos que propalam a solução para esta difícil equação, como é o caso do projeto urbanístico, localizado em São Caetano do Sul (área metropolitana de São Paulo, Brasil), que através do conceito "work, live and play", ou "moradia, trabalho, e lazer", busca associar estas três dimensões do viver em um único espaço. ${ }^{3}$

Interessante observar nas imagens de divulgação, o ideal de moradia, de trabalho e de lazer dos futuros habitantes deste espaço que inclui construções residenciais de alto padrão e áreas comerciais e de lazer, este inclusive, visivelmente articulado à ideia de consumo. Não por acaso, o projeto considerado o maior de "revitalização urbana do país" conta com uma grande área destinada à construção de um shopping center e, na imagem fotográfica que retrata o lazer, há uma moça sorridente carregando algumas sacolas de compras, fazendo explícita alusão ao lazer de consumo.

Este quadro contrasta com os anseios da maior parte da população para fruição do lazer, a qual em razão dos apelos da mídia se transforma em aspiração para muitos que, dado as condições de trabalho e, por vezes de não-trabalho, não tem acesso a este.

Tal paradoxo se coloca também de forma ameaçadora ao trabalhador quando, sob 0 discurso da qualidade de vida, porém com veladas e, por vezes, explícitas intenções de aumento da produtividade e/ou diminuição dos prejuízos com faltas médicas, algumas empresas adotam estratégias para transformar o próprio local de trabalho em "espaço de lazer", com desenvolvimento de ginástica laboral e realização de atividades recreativo-esportivas.

No entanto, tais iniciativas parecem reduzir as potencialidades do lazer para os trabalhadores, enquanto uma vivência emancipatória que em sua essência está ligada à ideia da liberdade, autonomia e espontaneidade.

\footnotetext{
${ }^{3}$ Fonte: Disponível em: <www.espacoceramica.com.br $>$ Acesso em: 28 abr. 2010.
} 
Para Lemos e Gonçalves Junior (2011), as potencialidades emancipatórias do lazer advêm, historicamente, do delineamento deste:

[...] em função de um tempo de não-trabalho, de um tempo em contraponto ao trabalho produtivo, sendo vislumbrado como um dos poucos momentos de realização e prazer [...] com possibilidades de se constituir em um tempo de reflexão e crítica desse e dos interesses econômicos envolvidos (p.147).

Nesse sentido compartilhamos com Santos e Gonçalves Junior (2008) quando observam que nas compreensões de lazer tem se notado uma valorização de, basicamente, quatro aspectos: tempo, espaço, atividade e atitude. No entanto, entendem que a vivência do lazer não deve ser fragmentada em tempo (de trabalho $x$ livre/disponível), tampouco circunscrita a espaços (equipamentos específicos de lazer $\mathrm{x}$ outros espaços), ou classificada em atividades (não sérias $x$ sérias), mas prioritariamente enquanto atitude, ou seja, a intencionalidade do ser.

Explicitamos, porém, reconhecer que um dos elementos mais nefastos desencadeados pela globalização da economia nos moldes em que se encontra, é o desemprego, gerado ora pelas novas tecnologias que eliminam postos de trabalho, ora pelas deslocalizações de empresas em busca de regiões ou países com mão de obra mais barata e menos organizada/combativa, ora pelo fechamento/falência de empresas. $E$, quem se encontra desempregado, embora possa a olhos desavisados passar a impressão de maior disponibilidade de tempo para fruição do lazer, por não estar trabalhando, depara-se com a premente necessidade de usar o tempo para atualizar-se para novamente inserir-se no mercado de trabalho, exercer trabalhos informais ou provisórios e, principalmente, procurar emprego efetivo, sem contar a baixa estima, por vezes configurando quadros de depressão, gerada na pessoa decorrente da forte valorização do trabalho/emprego em nossa sociedade.

A necessidade da constante atualização profissional imposta pelo empresariado em geral, particularmente 0 relacionado às corporações transnacionais ${ }^{4}$, àqueles que estão empregados para continuarem empregados, acentuada pela competitividade desencadeada com a globalização, tem dificultado a vivência do lazer e tornado mais distante a compreensão do lazer enquanto não dicotômico do trabalho.

Vale salientar que, ao conceber o lazer do ponto de vista histórico-social, não é possível

\footnotetext{
4 A expressão "transnacional" refere-se às grandes corporações originárias dos países desenvolvidos com atuação em escala global (GONÇALVES, 2002).
}

desvinculá-lo das lutas por esse direito, socialmente enraizado nas dicotômicas categorias tempo de trabalho e tempo de lazer, o que não significa afirmar que os tempos "institucionalizados" garantam uma vivência gratificante e qualitativa de lazer (LEMOS; GONÇALVES JUNIOR, 2011).

Contudo, para além do reconhecimento da conquista do tempo para o lazer, o que está em pauta é a possibilidade de entendimento deste lazer sob a perspectiva da intencionalidade, que põe em foco o Ser Humano e suas relações dotadas de sentido, em um constante movimento de vir a ser, objetivando uma sociedade humanizada, com melhores condições de vida e, consequentemente, de fruição da prática social lazer (RODRIGUES; LEMOS; GONÇALVES JUNIOR, 2010; LEMOS; GONÇALVES JUNIOR, 2011).

Na categoria "C) Lazer como recuperação para - trabalho", seis líderes sindicais emitiram asserções relacionadas ao lazer enquanto um tempo de descanso para recuperação das forças para voltar ao trabalho e não enquanto um fim em si mesmo.

Com base no estudo, consideramos que, nos tempos de globalização, após diversas conquistas dos trabalhadores (redução da jornada de trabalho, férias, organização sindical, estabilidade no emprego, entre outras), realizadas principalmente ao longo do século $X X$, configurando o que veio a se denominar "Estado de Bem-Estar Social", infelizmente, temos assistido, nas últimas décadas, crescente precarização (terceirização dos serviços, subcontratação, deslocalização das empresas, retração da ação sindical, ameaça ideológicaaterrorizante do desemprego) de direitos dos trabalhadores nos dois países pesquisados, gerando insegurança do trabalhador diante da vivência do seu trabalho e do seu lazer de modo autônomo, livre, criativo, significativo e humanizado, já que uma e outra prática social interpenetram-se na existência do ser, ou melhor, do sendo-uns-com-os-outros-ao-mundo.

Percebemos, no entanto, entre os sujeitos entrevistados, e que se mostrou como singular no que se refere ao sentido atribuído ao lazer, a resistência ao "neg-ócio", observando brechas e sendas do sistema para fruir de modo significativo o lazer e o trabalho, valendo-se da solidariedade e companheirismo junto a outros, fazendo um churrasquinho no final de semana quando bate

\footnotetext{
${ }^{5}$ A palavra "negócio" é originada a partir do prefixo "neg", de negação, e do sufixo "ócio", significando a negação do ócio para privilegiar o trabalho financeiramente lucrativo.
} 
uma laje, conforme destacou Edison Luiz Bernardes (Presidente do "Sindicato dos Trabalhadores nas Indústrias da Construção e do Mobiliário de São Caetano do Sul"), afinal, o ser humano compreendido por nós é aquele inacabado e condicionado "[...] porque, inacabado, sei que sou um ser condicionado mas, consciente do inacabamento, sei que posso ir além dele. Esta é a diferença profunda entre ser condicionado e o ser determinado." (FREIRE, 2005, p.53).

E nesse movimento de constante possibilidade de mudança no interior das práticas sociais, tais como trabalho e lazer, percebemos nos discursos dos líderes sindicais das áreas metropolitanas de Lisboa (Portugal) e São Paulo (Brasil) significação do lazer fortemente atrelada a resistência, reflexão e superação do modelo dicotômico atual, embora pelas próprias circunstâncias históricas neste contexto de globalização, por vezes expressam o fenômeno lazer prioritariamente em sua dimensão de tempo (chrono's ${ }^{6}$ ) oposto ao de trabalho, todavia, emergindo de dentro dele, subvertendo-o para a humanização das relações humanas no labor e primando para uma vida plena de sentido no trabalho e no lazer.

\section{Referências}

ADORNO, T. W. Palavras e sinais: modelos críticos. 2. ed. Rio de Janeiro: Vozes, 1995.

ALMEIDA, M. A. B. de; GUTIERREZ, G. L. O lazer no Brasil: do nacional-desenvolvimentismo à globalização. Conexões, Campinas, v. 3, n. 1, p. 36-57, 2005.

ANTUNES, R. Adeus ao trabalho?: ensaio sobre as metamorfoses e a centralidade do mundo do trabalho. 6. ed. São Paulo: Cortez; Campinas: Edunicamp, 1999.

\section{CORRÊA, D. A. Domingo no parque: a}

(sobre)vivência do lazer nos parques públicos municipais da Zona Leste da cidade de São Paulo (1970-2002). 2002. 90 f. Dissertação (Mestrado em História Social) - Pontifícia Universidade Católica de São Paulo, São Paulo, 2002.

DUMAZEDIER, J.. Lazer e cultura popular. São Paulo: Perspectiva, 1973.

FREIRE, P. Pedagogia da autonomia. 31. ed. São Paulo: Paz e Terra, 2005.

GIANOTTI, V. O que é estrutura sindical. 2. ed. São Paulo: Brasiliense, 1988.

\footnotetext{
${ }^{6}$ Informação fornecida por J. Martins no evento O envelhecer na PUC, em São Paulo, em abril de 1991.
}

GONÇALVES, R. A empresa transnacional. In: KUPFER, D.; HASENCLEVER, L. (Org.).

Economia industrial: fundamentos teóricos e práticos no Brasil. 7. ed. reimp. Rio de Janeiro: Elsevier, 2002. p. 389 - 411.

GONÇALVES JUNIOR, L. Lazer e trabalho: a perspectiva dos líderes das centrais sindicais do Brasil e de Portugal em tempos de globalização. In: _. (Org.) Interfaces do lazer: educação, trabalho e urbanização. São Paulo: Casa do Novo Autor, 2008. p. 54 -108.

GONÇALVES JUNIOR, L.; SANTOS, M. O. Brincando no jardim: processos educativos de uma prática social de lazer. In: EDUCERE CONGRESSO NACIONAL DE EDUCAÇÃO PUCPR - PRAXIS, 6., 2006, Curitiba. Anais... Curitiba: PUCPR, 2006. p. 1543 - 1555.

HUSSERL, E.. Investigações lógicas: sexta investigação: elementos de uma elucidação fenomenológica do conhecimento. São Paulo: Nova Cultural, 1988. (Os pensadores, v. 41).

IANNI, O. A era do globalismo. Rio de Janeiro: Civilização Brasileira, 1997.

LAFARGUE, P. O direito à preguiça. São Paulo: Hucitec: Unesp, 1999.

LEMOS, F. R. M.; GONÇALVES JUNIOR, L.. Desvelando experiências de lazer de trabalhadores de indústrias transnacionais. In: GONÇALVES JUNIOR, L.; CORRÊA, D.; RODRIGUES, C. (Org.) Educação e experiência: construindo saberes em diferentes contextos. Curitiba: CRV, 2011. p.147 - 170.

LIMA, M. P. de. Reflexões sobre a negociação colectiva e a concertação social em Portugal. In: DORNELAS, A.; PINTO, J. M. (Coord.) A reforma do pacto social. Lisboa: Imprensa Nacional, 1999. p. 301 - 374.

LIMA, M. P. de et al. A acção sindical e o desenvolvimento: uma intervenção sociológica em Setúbal. Lisboa: Salamandra, 1992.

LIMA, M. P. de et al. A organização da indústria automóvel na península de Setúbal. Análise Social: revista do ICS/UL, v. 31, n. 139, p. 11171181. 1996.

MARCELLINO, N. (Org.) Políticas públicas setoriais de lazer: o papel das prefeituras. Campinas: Autores Associados, 1996.

MARTINS, J. Um enfoque fenomenológico do currículo: educação como "poíesis". São Paulo: Cortez, 1992. 
MARTINS, J. B., BICUDO, M. A. V. A pesquisa qualitativa em psicologia: fundamentos e recursos básicos. São Paulo: Moraes: EDUC, 1989.

MERLEAU-PONTY, M. Fenomenologia da percepção. 2. ed. São Paulo: Martins Fontes, 1996.

MONIZ, A. B. A contribuição da sociologia para a formação em engenharia. Organizações e Trabalho, Lisboa, n. 27. p. 9-37, 2002.

OBSERVATÓRIO do emprego e formação profissional. Os trabalhadores de meia idade face às reestruturações e políticas de gestão de recursos humanos. Lisboa: Grafifina, 2001. (Colecção Estudos e Análises, v. 30).

PAIS, J. M. Ganchos, tachos e biscates: jovens, trabalho e futuro. Porto: Âmbar, 2001.

RODRIGUES, I. J. Sindicalismo e política: a trajetória da CUT. São Paulo: Scritta: FAPESP, 1997.

RODRIGUES, C.; LEMOS, F. R. M.; GONÇALVES JUNIOR, L.. Teorias do lazer: contribuições da fenomenologia. In: PIMENTEL, G. G. de A. (Org.) Teorias do lazer. Maringá: Eduem, 2010. p.73-102.

ROSÁRIO, A. T. do. O desporto em Portugal: reflexo e projecto de uma cultura. Lisboa: Instituto Piaget, 1996.

RUSSELL, B. Elogio ao ócio. In: DE MASI, D. A economia do ócio: Bertrand Russell \& Paul Lafargue. Rio de Janeiro: Sextante, 2001. p. 47137.

SANTOS, M. O.; GONÇALVES JUNIOR, L.. Vivências em atividades diversificadas de lazer: trajetória histórica de um projeto de extensão. In: ENCONTRO NACIONAL DE RECREAÇÃO E LAZER (ENAREL), 20., 2008, São Paulo. Anais... São Paulo: SESI, 2008.

SILVA, M. C. da. Agir contra a corrente: reflexões de um sindicalista. Porto: Campo das Letras, 2002.

TÁPIA, L. E. R. Método em fenomenologia. In: MARTINS, J.; DICHTCHEKENIAN, M. F. S. F. Temas fundamentais da fenomenologia. São Paulo: Moraes, 1984. p. 69 - 74.
Endereço:

Luiz Gonçalves Junior

Universidade Federal de São Carlos

Rodovia Washington Luiz, Km 235

São Carlos SP Brasil

13565-905 Caixa Postal: 676

Telefone: (16) 3351.8769 Fax: (16) 3351.8294

e-mail: luiz@ufscar.br

Recebido em: 2 de junho de 2010.

Aceito em: 20 de abril de 2011.

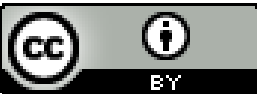

Motriz. Revista de Educação Física. UNESP, Rio Claro, SP, Brasil - elSSN: 1980-6574 - está licenciada sob Creative Commons - Atribuição 3.0 